\section{The role of temporal artery biopsy in patients with giant-cell arteritis is debated}

Over a few decades, temporal artery biopsy (TAB) was regarded as the gold standard for diagnosis of giant-cell arteritis (GCA). However, is it really necessary to use this invasive test in all patients with GCA, particularly in those with typical clinical features of the disease? Can we replace TAB with imaging modalities, including ultrasound and $\left[{ }^{18} \mathrm{~F}\right]$-fluorodeoxyglucose positron emission tomography (PET), that are more sensitive and/or more readily available in many institutions? Dejaco et al said yes in the recently published European League Against Rheumatism recommendations for the use of imaging in large-vessel vasculitis in clinical practice. ${ }^{1}$ The authors suggested that in patients in whom there is a high clinical suspicion of GCA and a positive ultrasound, the diagnosis of GCA may be made without biopsy or further imaging. Other imaging modalities, that is, PET and/or MRI, are more valuable in patients with Takayasu-like GCA without cranial signs and symptoms. Noteworthy, the task force clearly emphasised that TAB should be performed in all cases, where GCA cannot be confirmed or excluded based on clinical, laboratory and imaging results. Moreover, TAB should still be a preferred diagnostic test in the settings where expertise with imaging in GCA is questionable. Therefore, rheumatologists can choose the optimum first-line diagnostic strategy (ultrasound-guided or TAB-based) taking into account the available resources and expertise.

Apparently, not all experts will agree with a proposed diagnostic algorithm. In the other recent recommendations for the management of GCA published by the French Study Group for Large Vessel Vasculitis (GEFA), Bienvenu et al suggested that imaging of the temporal artery does not support the GCA diagnosis with as much certainty as TAB. ${ }^{2}$ In France, Doppler ultrasound is little used and has yielded mixed results, ${ }^{3}$ while MRI is more expensive and less available than ultrasound. However, the authors commented that no real consensus exists on the histological criteria defining GCA.

In the pivotal tocilizumab trial (GiACTA), the diagnosis of GCA was based on the results of TAB or on evidence of large-vessel vasculitis on imaging methods. ${ }^{4}$ A proportion of patients with GCA that was established by means of positive imaging were 46\%. Apparently, the investigators who participated in this important study used non-invasive modalities (ie, CT angiography, MR angiography or PET) not only for diagnosis of the large-vessel GCA, given a high occurrence of cranial symptoms in the eligible patients (79\%). Noteworthy, protocol of GiACTA study did not define ultrasound as a confirmatory diagnostic test for GCA. The GiACTA trial led to the approval of tocilizumab for the treatment of GCA in the USA, the European Community and the UK. Therefore, the regulatory authorities have recognised the role of imaging modalities in the diagnosis of GCA.

In our opinion, the European League Against Rheumatism recommendations legitimise the existing clinical approach to the diagnosis of GCA in a real-life setting. A proportion of patients with TAB-positive GCA are usually very high in the published research articles. However, it seems to be a significantly lower in the routine clinical practice. Furthermore, the results of several studies suggest that TAB does not affect management in the majority of patients with suspected GCA, ${ }^{5}$ that is, in one series, $87 \%$ of biopsy-negative patients continued prednisolone therapy on clinical grounds. ${ }^{6}$
In our centre, we prefer to use PET as a second-line imaging modality in ultrasound-negative patients with suspected GCA. ${ }^{7}$ This method allows both to identify vasculitis of the large arteries and to rule out infections or tumours that can be associated with constitutional symptoms and laboratory findings typical for GCA. Moreover, PET may be helpful for monitoring of disease activity, though it is still unclear whether ongoing tracer uptake despite immunosuppressive treatment reflects low-grade inflammation or remodelling. ${ }^{1}$ Disadvantages of PET that include high costs, radiation exposure and possible diagnostic errors in the elderly patients with atherosclerosis should also be appreciated.

In patients with suspected Takayasu's arteritis (TAK), the task force recommended to use MRI as the first imaging test to make a diagnosis. We agree with the authors that MRI is particularly valuable to investigate mural inflammation and/or luminal changes. However, ultrasound seems to have a similar diagnostic utility. In our own cohort, approximately $80 \%$ of 126 patients with TAK presented with stenosis of subclavian or carotid arteries that are easily accessible to ultrasound examination. Similar findings were obtained in the large cohort of Chinese patients with TAK $(n=411){ }^{8}$ According to the recent meta-analysis, ultrasound had a lower pooled sensitivity than MRI $(81 \%$ vs $92 \%$ ) for TAK diagnosis. However, both methods had very high specificity of $>90 \%{ }^{9}$

In summary, patients and many physicians will probably welcome new recommendations for the use of imaging in patients with GCA in clinical practice, given a possibility to avoid a burden associated with an invasive intervention. The potential cost savings should not also be disregarded, since ultrasound in all patients with suspected GCA has been reported as cost-effective compared with biopsy plus clinical judgement alone with a net monetary benefit of $£ 485$ ( $€ \sim 550$ / US $\$ \sim 600$ ) per patient. $^{10}$ The recommendations did not intend to discredit the role of TAB in the diagnosis of GCA. However, we strongly agree with the task force that personalised approach to diagnosis may be implemented in different centres based on the available modalities and expertise.

Sergey V Moiseev, ${ }^{1}$ Ilya Smitienko, ${ }^{2}$ Nikolay Bulanov, ${ }^{1}$ Pavel I Novikov ${ }^{1}$

${ }^{1}$ Clinic of Nephrology, Internal and Occupational Diseases, Sechenov First Moscow State Medical University, Moscow, Russia

${ }^{2} \mathrm{~K}+31$ Medical Center, Moscow, Russia

Correspondence to Professor Sergey V Moiseev, Clinic of Nephrology, Internal and Occupational Diseases, First Moscow State Medical University, Moscow 119435, Russia; clinpharm@mtu-net.ru

Handling editor Josef S Smolen

Contributors All authors participated in the preparation of the comment.

Funding This research received no specific grant from any funding agency in the public, commercial or not-for-profit sectors.

Competing interests None declared.

Patient consent Not required.

Provenance and peer review Not commissioned; internally peer reviewed.

(c) Article author(s) (or their employer(s) unless otherwise stated in the text of the article) 2019. All rights reserved. No commercial use is permitted unless otherwise expressly granted.

\section{Check for updates}

To cite Moiseev SV, Smitienko I, Bulanov N, et al. Ann Rheum Dis 2019;78:e31.

Received 21 February 2018

Accepted 21 February 2018

Published Online First 2 March 2018 


\section{SLinked}

- http://dx.doi.org/10.1136/annrheumdis-2018-213284

Ann Rheum Dis 2019;78:e31. doi:10.1136/annrheumdis-2018-213282

\section{REFERENCES}

1 Dejaco C, Ramiro S, Duftner C, et al. EULAR recommendations for the use of imaging in large vessel vasculitis in clinical practice. Ann Rheum Dis 2018;77:636-43

2 Bienvenu B, Ly KH, Lambert M, et al. Management of giant cell arteritis: recommendations of the French Study Group for Large Vessel Vasculitis (GEFA). Rev Med Interne 2016:37:154-65.

3 Maldini C, Dépinay-Dhellemmes C, Tra TT, et al. Limited value of temporal artery ultrasonography examinations for diagnosis of giant cell arteritis: analysis of 77 subjects. J Rheumatol 2010;37:2326-30.
4 Stone $\mathrm{JH}$, Tuckwell K, Dimonaco $\mathrm{S}$, et al. Trial of tocilizumab in giant-cell arteritis. $N$ Engl J Med 2017;377:317-28.

5 Bowling K, Rait J, Atkinson J, et al. Temporal artery biopsy in the diagnosis of giant cell arteritis: Does the end justify the means? Ann Med Surg 2017;20:1-5.

6 Quinn EM, Kearney DE, Kelly J, et al. Temporal artery biopsy is not required in all cases of suspected giant cell arteritis. Ann Vasc Surg 2012;26:649-54.

7 Novikov PI, Meshkov AD, Moiseev SV. Positron emission tomography in giant cell arteritis: a new diagnostic tool? Ann Rheum Dis 2014;73:e70.

8 Li J, Sun F, Chen Z, et al. The clinical characteristics of Chinese Takayasu's arteritis patients: a retrospective study of 411 patients over 24 years. Arthritis Res Ther 2017; 19:107.

9 Barra L, Kanji T, Malette J, et al. Imaging modalities for the diagnosis and disease activity assessment of Takayasu's arteritis: A systematic review and meta-analysis. Autoimmun Rev 2018;17:175-87.

10 Luqmani R, Lee E, Singh S, et al. The role of ultrasound compared to biopsy of temporal arteries in the diagnosis and treatment of giant cell arteritis (TABUL): a diagnostic accuracy and cost-effectiveness study. Health Technol Assess 2016;20:1-238. 